\title{
Cancers among South-East Asian Nationals in Brunei Darussalam
}

\author{
Vui Heng Chong1*, Pemasari Upali Telisinghe ${ }^{2}$, Edwin Lim² ${ }^{2}$,Jackson Tan ${ }^{1}$, Chee \\ Fui Chong ${ }^{3}$
}

\begin{abstract}
Background: Worldwide, the incidence of cancers is increasing and is becoming a major public health issue, including those in the Asia Pacific region. South-East Asia is a region with diverse populations with different disease spectra. This study looked at the spectrum of cancers among South-East Asians working in Brunei Darussalam. Materials and Methods: The cancer registry from 1994 to 2012 maintained by the State Laboratory was retrospectively reviewed. Crude incidence rates were calculated based on the population census of 2010 . Results: Altogether, there was a total of $\mathbf{4 1 8}$ cancer cases diagnosed among South-East Asians, giving an incidence of 5.1\% $(n=418 / 8,253)$. The affected nationals in decreasing frequency were Malaysians $(53.1 \%)$, followed by Filipinos (25.8\%), Indonesians (15.3\%), Thais $(3.8 \%)$, Myanmese $(1.7 \%)$ and Vietnamese $(0.2 \%)$ with no recorded cases for Singapore and the People's Republic of Laos. The overall mean age of diagnosis was 46.1 \pm 4.2 years old, with an increasing trend over the years ( $p<0.05$ ANOVA). The overall gender ratio was 42.3:57.7 (male:female), more females among the Filipinos and Indonesians, more males among the Thais, and equal representation among the Malaysians and the Myanmese. The most common were cancers of the digestive system (19.9\%), followed by female reproductive/gynecologic system (16.0\%), breast (15.6\%), hematological/lymphatic (12.0\%) and head/neck $(8.1 \%)$. There were differences in the prevalence of cancers among the various nationalities with highest crude incidence rate among the Myanmese (141.2/100,000), followed by the Malaysian $(88.5 / 100,000)$, and the Filipinos $(40.6 / 100,000)$ and the lowest among the Thais $(18.4 / 100,000)$, Indonesians $(10.5 / 100,000)$ and the Vietnamese $(6.3 / 100,000)$. Conclusions: Cancers among South-East Asian residing in Brunei Darussalam accounted for $5.1 \%$ of all cancers. The most common cancers were cancers of the digestive, gynecologic/female reproductive system and breast with certain types slowly increasing in proportions. There mean age of diagnoses was increasing.
\end{abstract}

Keywords: Southeast Asia - neoplasms - cancers - spectrum - Brunei Darussalam

Asian Pac J Cancer Prev, 17 (2), 845-849

\section{Introduction}

Cancer is an important cause of morbidity and mortality worldwide. The incidence is increasing as results of ageing population and change in lifestyles, (Woodward, 2014) and is becoming an important health care issue in many developing nations. In 2012, there were an estimated 14.1 million new cancer cases and 8.2 million cancer related deaths worldwide (IARC, 2012). Of these, $57 \%$ ( 8 million) of the new cancer cases, $65 \%$ (5.3 million) of the cancer deaths and $48 \%$ (15.6 million) of the 5-year prevalent cancer cases occurred in the less developed regions, which include South-East Asia (IARC, 2012). Based on the WHO SEARO data (IARC 2012), 1.724 million cancer cases were estimated to have occurred in the South-East Asia Region, accounting for $12.2 \%$ of the global cancer burden.
South-East Asia comprise of the member nations of the Association of South-East Asian Nations (ASEAN), and consist of Brunei Darussalam, Malaysia, Singapore, Thailand, The Philippines, Indonesia, Viet Nam, Myanmar, People's Republic of Laos and Cambodia. South-East Asia is diverse with population of different ethnicities and different genetic makeups and cultures (Moore et al., 2011; Woodward, 2014). However, there are also similarities (Moore et al., 2012). Population movements within the region are common and with the increasing economic collaborations, the trend will increase. Even though, the expatriate population accounts for a small proportion of a population in most countries, it is important to be aware of the spectrum of disorders, including cancers, for future health planning and to understanding cancer characteristics in the global setting. International (IARC, 2012; Moore et al., 2012;) and country level (National 
Vui Heng Chong et al

Cancer Registry Singapore 2008-2012; National Cancer Registry Malaysia 2007) including hospital or regional level data have shown increasing and changing spectrum of cancers in the South-East Asia regions (Othman et al., 2008; Laudico et al., 2010; Wirasorn et al., 2010; Wahidin et al., 2012; Teo and Soo, 2013; Vuong et al., 2014). Studies on immigrant populations have shown the cancer patterns initially resemble the countries of origin, but with time with adoption of the new lifestyle, the pattern starts to change resembling the countries of residence (Ali et al., 2012; Maringe et al., 2012; Giddings et al., 2013; Menon et al., 2013). To date, there is no data on among non-immigrant South-East Asians working in Brunei Darussalam. This study assessed the spectrum of cancers seen among the non-immigrants South-East Asian nationals working in Brunei Darussalam.

\section{Materials and Methods}

Setting: Brunei Darussalam is a small developing nation with a total area of $5,765 \mathrm{~km} 2$ and estimated population of 415,717 (July 2013; Department of Economic Planning, Ministry of Finance). The population breakdown consists of ethnic group (Malays 66.3\%, ethnic Chinese $11 \%$ and indigenous $2.7 \%$ ) and the expatriate group (20\%). The expatriate group consisted mainly of those from the neighbouring South-East Asia countries and South Asia. A detailed census (Department of Economic Planning, Ministry of Finance) showed that South-East Asians (from the ASEAN region) numbered 65,362; Indonesia 32,058, Malaysian 13,206, The Philippines 14,005, Thailand 4,576, Viet Nam 833, Singapore 408, Myanmar 261, The People's Republic of Laos 6 and Cambodia 9.

Data source: The cancer registry maintained by the Department of Pathology were retrospectively review from 1994-2012. In this registry, only histology proven cancers are registered. Being the only state histopathology laboratory, the registry is for the whole country and therefore is representative.

Cancers categorization: For this study, the cancers were categorized into systems; Neurological (central and peripheral), Head and Neck (all cancer located in the head and neck region; including the upper aerodigestive tract), Gastrointestinal tract (esophagus to anus), Thorax (lung, mediastinal, airways and the pleural), Male Reproductive, Female Reproductive/Gynecologic, Urology, Skin and Appendages (including soft tissue), and Primary Tumor Unknown.

Statistic: The data were entered into the Wordexcel (Microsoft) and later transferred into the Statistical Package for Social Sciences (SPSS, Version 16.0, Chicago, IL USA) program for analysis. Chi-squared test was used to compare the categorical variables and the ANOVA and Mann-Whitney non-parametric test were used to compare the continuous variables. A p value of less than 0.05 was taken as significant.

\section{Results}

Over the study period, there were a total of 8,253
( $n=31$ excluded due to incomplete data) cancer cases diagnosed, of which 418 (5.1\%) were among South-East Asian nationals, ranging from $3.6 \%$ to $6.9 \%$ over the years.

The mean age at diagnosis among the South-East group was $46.1 \pm 4.2$ years old, significantly younger than the Bruneian group $(54.5 \pm 17.8$ years old, $\mathrm{p}<0.001)$. The gender ratio of among the South-East group (44.1\% Male: $55.9 \%$ Female), not different to the Bruneian group (male $44.0 \%$, female $56.0 \%, \mathrm{p}=0.285$ ). Comparing between the different South-East Asian nationals, The Myanmese had the highest mean age of diagnosis and the youngest being

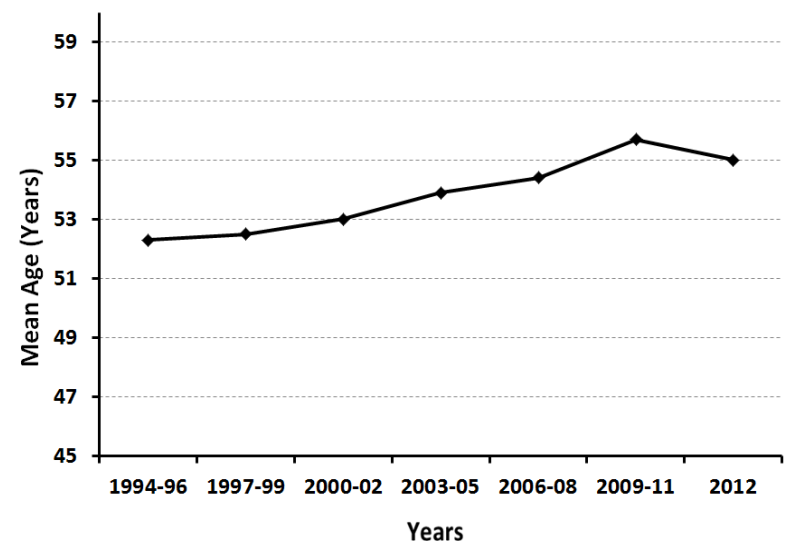

Figure 1. The Mean age of Diagnosis of Cancers in South-East Asian Nationals Over the Years

Table 1. Demographic of Patients and the Mean Age of Diagnosis among the Various Groups

\begin{tabular}{lrrcc}
\hline & Total & \multicolumn{2}{c}{ Gender $\mathrm{n}(\%)$} & Mean age \\
& & Men & Women & of diagnosis \\
\hline Malaysian & 222 & $111(50.0)$ & $111(50.0)$ & $49.2 \pm 15.9$ \\
Indonesian & 64 & $16(25.0)$ & $48(75.0)$ & $38.8 \pm 9.5$ \\
Filipinos & 108 & $32(29.6)$ & $76(70.4)$ & $43.7 \pm 9.9$ \\
Thais & 16 & $14(87.5)$ & $2(12.5)$ & $40.6 \pm 9.2$ \\
Myanmese & 7 & $3(42.9)$ & $4(57.1)$ & $60.6 \pm 13.1$ \\
Vietnamese & 1 & $1(51.0)$ & $-(-)$ & 51 \\
Bruneians & 7,804 & $3,424(43.9)$ & $4,380(56.1)$ & $(54.5 \pm 17.8)$ \\
Singaporean & 0 & 0 & 0 & - \\
Cambodian & 0 & 0 & 0 & - \\
PR of Laos & 0 & 0 & 0 & - \\
\hline
\end{tabular}

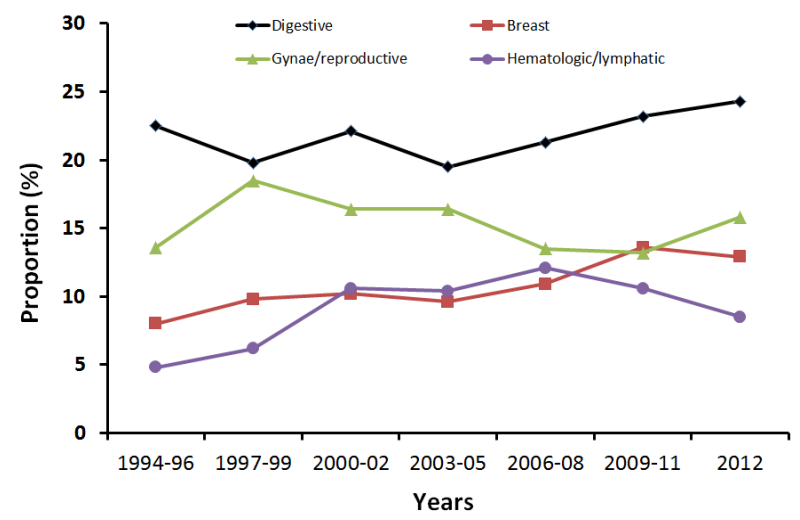

Figure 2. The Porportion of the Top Four Most Common Cancers (Systems) for the South-East Asian Nationals Over the Years 
DOI:http://dx.doi.org/10.7314/APJCP.2016.17.2.845

Table 2. The Crude Incidence Rates among the different South-East Asians nationals

\begin{tabular}{lc}
\hline Nationalities & Crude Incidence rates (per 100,000) \\
\hline Myanmese & 141.2 \\
Malaysians & 88.5 \\
Filipinos & 40.5 \\
Thais & 18.4 \\
Indonesians & 10.5 \\
Vietnamese & 6.3 \\
\hline
\end{tabular}

Cancers among South-East Asian Nationals in Brunei Darussalam the Indonesians. The mean age of diagnosis for the SouthEast Asian nationals was increasing $(\mathrm{p}<0.05$ ANOVA) over the years (Figure 1).

The gender breakdown and the mean age of diagnoses among the various South-East Asian nationals are shown in Table 1. The affected nationals in decreasing frequency were the Malaysians $(53.1 \%)$, followed by Filipinos (25.8\%), Indonesians (15.3\%), Thais (3.8\%), Myanmese $(1.7 \%)$ and Vietnamese $(0.2 \%)$ with no recorded case for Singapore, Republic of Laos and Cambodia. The highest

Table 3. Types of Cancers among the various South-East Asian Nationals in Brunei Darussalam

\begin{tabular}{|c|c|c|c|c|c|c|c|c|}
\hline Systems & Nationals & Malaysian & Indonesian & Filipinos & $\begin{array}{c}\text { Thais } \\
\text { n (Male / } \\
\text { Female) }\end{array}$ & Myanmese & Vietnamese & Overall \\
\hline Neurological & & $3(2 / 1)$ & $1(1 / 0)$ & 0 & 0 & 0 & 0 & $4(3 / 1)$ \\
\hline Digestive & & $48(39 / 9)$ & $11(7 / 4)$ & $15(7 / 8)$ & $5(5 / 0)$ & $3(3 / 0)$ & $1(1 / 0)$ & $83(62 / 21)$ \\
\hline Thorax & & $21(9 / 12)$ & $1(0 / 1)$ & $4(3 / 1)$ & $3(3 / 0)$ & 0 & 0 & $29(15 / 13)$ \\
\hline Breast & & $17(0 / 17)$ & $19(0 / 19)$ & $29(0 / 29)$ & 0 & 0 & 0 & $65(0 / 65)$ \\
\hline Male Reproductive & & $6(0 /-)$ & $3(3 /-)$ & $3(3 /-)$ & 0 & 0 & 0 & $12(12 /-)$ \\
\hline $\begin{array}{l}\text { Female Reproductive/ } \\
\text { Gynecologic }\end{array}$ & & $33(-/ 33)$ & $12(-/ 12)$ & $20(-/ 20)$ & $1(-/ 1)$ & $1(-/ 1)$ & 0 & $67(-/ 67)$ \\
\hline $\begin{array}{l}\text { Hematologic/ } \\
\text { Lymphatic }\end{array}$ & & $25(16 / 9)$ & $7(1 / 6)$ & $16(4 / 12)$ & $1(1 / 0)$ & $1(0 / 1)$ & 0 & $50(22 / 28)$ \\
\hline Head and Neck & & $23(15 / 8)$ & $4(2 / 2)$ & $4(4 / 0)$ & $3(3 / 0)$ & 0 & 0 & $34(24 / 10)$ \\
\hline $\begin{array}{l}\text { Skin and Appendages/ } \\
\text { Subcutaneous }\end{array}$ & & $21(11 / 10)$ & $5(2 / 3)$ & $7(5 / 2)$ & $2(1 / 1)$ & $2(0 / 2)$ & 0 & $37(19 / 18)$ \\
\hline Urology & & $8(6 / 2)$ & 0 & $3(3 / 0)$ & 0 & 0 & 0 & $11(9 / 2)$ \\
\hline Endocrine & & $11(2 / 9)$ & 0 & $5(2 / 3)$ & 0 & 0 & 0 & $16(4 / 12)$ \\
\hline $\begin{array}{l}\text { Primary Tumor } \\
\text { Unknown }\end{array}$ & & $6(5 / 1)$ & $1(0 / 1)$ & $2(1 / 1)$ & $1(1 / 0)$ & 0 & 0 & $10(7 / 3)$ \\
\hline Total & & $\begin{array}{c}222 \\
(111 / 111)\end{array}$ & $64(16 / 48)$ & $\begin{array}{c}108 \\
(32 / 76)\end{array}$ & $\begin{array}{c}16 \\
(14 / 2)\end{array}$ & $7(3 / 4)$ & $1(0 / 1)$ & $\begin{array}{c}418 \\
(177 / 241)\end{array}$ \\
\hline
\end{tabular}

Data in Bracket represent gender breakdown (Male/Female)

Table 4. The Crude Incidence Rates among the Different South-East Asians Nationals Based on the IARC data (2012)

\begin{tabular}{|c|c|c|}
\hline Nationalties & $\begin{array}{l}\text { Crude Incidence } \\
\text { Rates (per } 100,000)\end{array}$ & Top five cancers (excluding non-melanoma skin cancers) \\
\hline Myanmese & 90.2 & $\begin{array}{l}\text { Breast (26.0), Cervix uteri (21.1), Colorectum (6.4), Stomach (5.5), } \\
\text { Ovary (5.3) }\end{array}$ \\
\hline Malaysia & 104.6 & $\begin{array}{l}\text { Breast (45.7), Cervix uteri (15.5), Colorectum (13.4), Prostate (8.4), } \\
\text { Nasopharynx (7.2) }\end{array}$ \\
\hline Filipinos & 91.5 & $\begin{array}{l}\text { Breast (49.6), Cervix uteri (16.4), Prostate (11.2), Colorectum (8.5), } \\
\text { Uterus (6.2) }\end{array}$ \\
\hline Thais & 149.4 & $\begin{array}{l}\text { Breast (46.2), Cervix uteri (26.3), Prostate (18.5), Colorectum (17.7), } \\
\text { Lung (15.2) }\end{array}$ \\
\hline Indonesia & 96.7 & $\begin{array}{l}\text { Breast (46.3), Cervix uteri (16.7), Prostate (11.7), Colorectum (9.2), } \\
\text { Ovary (7.6) }\end{array}$ \\
\hline Vietnam & 86.7 & $\begin{array}{l}\text { Breast (27.7), Cervix uteri (11.0), Lung (9.6), Stomach (8.4), Colorectum } \\
\text { (7.8) }\end{array}$ \\
\hline Cambodia & 80.7 & $\begin{array}{l}\text { Cervix uteri (21.3), Breast (21.0), Colorectum (5.4), Liver (5.1), Ovary } \\
(4.0)\end{array}$ \\
\hline People's Republic of LOA & 63.9 & $\begin{array}{l}\text { Breast (18.9), Cervix uteri (11.0), Liver (11.0), Colorectum (5.3), Ovary } \\
(4.2)\end{array}$ \\
\hline Singapore & 234.0 & $\begin{array}{l}\text { Breast (106.8), Prostate (48.7), Colorectum (44.9), Uterus (21.4), Ovary } \\
(13.0)\end{array}$ \\
\hline
\end{tabular}

Figures presented in parentheses are rates per 100,000 
crude incidence rate was among the Myanmese, followed by the Malaysian and the Filipinos, and the lowest rates in the Vietnamese. The Crude Incidence Rates is shown in Table 2.

Overall, the most common cancers were cancers of the digestive system (19.9\%), followed by female reproductive/gynecologic system (16.0\%), breast (15.6\%), hematological/lymphatic (12.0\%) and head/neck cancers $(8.1 \%)$. The least common were cancers of the urology system, male reproductive system and primary tumor unknown. Among women, the most common cancers were cancer of the breast, followed by cancer of the cervix whereas, among men, this was cancer of the digestive system, in particular colon and stomach. This is shown in Table 3.

Among the top four most common cancers, the proportions of breast, digestive and hematologic/lymphatic were increasing whereas gynecologic/reproductive was declining (Figure 2).

\section{Discussion}

Our study showed that cancers among South-East Asian nationals residing and working in Brunei Darussalam accounted for $5.1 \%$ of all the histologically proven cancers cases encountered over the 19 years period. Among the different nationalities, Malaysians (53.1\%) accounted for the highest proportion, followed by the Filipinos (25.8\%). Despite accounting for the largest number of South-East Asian nationals in Brunei Darussalam, the total number of cancers cases among the Indonesians accounted for only $15.3 \%$. The Crude Incidence Rates was highest among the Myanmese $(141.2 / 100,000)$, followed by the Malaysian $(88.5 / 100,000)$, and the Filipinos $(40.6 / 100,000)$. Compared to the rates reported by the IARC (Table 4 ) for the region (IARC 2012), our rates are very different. This is not unexpected considering our study looked at cancers spectrum among people living outside of their countries, a self-selected group not necessarily representative of the population of their countries of origin. Generally, the proportions of cancers were proportional to the total number and the demographics of the respective nationalities in the country.

The most common cancers were cancers of the digestive system, followed by female reproductive/ gynecologic system, breast, hematological/lymphatic and head/neck cancers. The most common cancers in the South-East Asia region (Table 4) based on crude incidence rates from the International Agency for Research on Cancers (IARC 2012) are cancers of the breast, cervix, prostate and colorectum. By far, the most common cancers are cancers affecting female with cancers of the breast and cervix, being the top two most common cancers in the various countries. Data from available cancer registries or studies from the South-East Asia regions have shown similar findings. The Malaysian National Cancer Registry of 2007 reported that breast cancer was the most common cancer accounting for $18.1 \%$, followed by colorectal cancer $(12.3 \%)$, trachea, bronchus and lung (10.2\%), nasopharyngeal carcinoma $(5.2 \%)$ and cervical cancer (4.6\%) as the top five common cancers (National Cancer
Registry Report, Malaysia 2007). In contrast, Singapore which the most developed nation in the South-East Asia region reported that common cancers were colorectal cancers, followed by cancers of the breast, lung, lymphoid tissue and prostate (Singapore Cancer Registry 2013). A study from Cambodia in 2012 reported that top five most common cancers were cervix, liver, lung, breast and stomach cancers (Eav et al., 2012). A study from Indonesia reported leading cancers were breast (ASR 18.6/100,000), cervix $(9.25 / 100,000)$, lung $(8.21 / 100,000)$, colorectal $(7.28 / 100,000)$ and liver cancers $(5.42 / 100,000)$ (Wahidin et al., 2012). Our study also shows that cancers affecting the breast and female reproductive/gynecological system were very common. Liver and biliary cancers which are reported to be common in mainland South-East Asia were uncommon in our study (Moore et al., 2011).

The differences between the rates reported by our study compared to the rate reported in the countries of origin can be accounted for by several factors; a) the demographic of these foreign nationals, in particular age, health status and socioeconomic status, and b) health seeking behaviors. Furthermore all foreign nationals are required to undergo and pass the mandatory medical fitness tests before being given employment passes.

Most of the non-immigrant foreign nationals in Brunei Darussalam, which also true for other countries are in the economically productive ages, and are generally healthy. The mean age of diagnosis among the SouthEast Asian group was $46.1 \pm 14.1$ years, much younger than the Bruneian group. Differences in the age groups between nationalities are also important. Among the different South-East Asian nationals, the youngest were the Indonesians (38.8 \pm 9.5 years) and the oldest being the Myanmese $(60.6 \pm 13.1$ years $)$. Overall, the mean age of diagnosis of cancers among the foreign nationals were increasing over the years (Figure 2). Apart from childhood cancers, most cancer incidence increase with age. Therefore, the findings of lower incidence of cancers among certain nationalities are not unexpected.

The types of employments are also reflections of the social economic standing, and hence health status and health seeking behaviors. Unfortunately, the cancer registry does not capture data on employment of patients. However, most Indonesians, Thais and Filipinos are blue collar workers in the service (restaurants, retails and domestic helpers) or construction industries whereas the Myanmese are mostly professionals in the healthcare sector. Among the other smaller groups, Singaporeans, Cambodian and Laotians are mostly professionals or work with the diplomatic services of their respective countries. Unlike the Indonesians, Thais and Filipinos, the Malaysian group also have many dependents (spouses, children and parents) living in the country, accounting for the older mean age of diagnosis.

Apart from patients' demographic, health seeking behaviors are also important determinants (Jung et al., 2013; Chang et al., 2014) in this group of population. For major illnesses, due to cost issue the less affluent group tend to go back to their homeland for investigations and treatment.

Overall, it is very important for clinicians and 
healthcare related organisations (Ministry of Health, other healthcare related government and non-government agencies) to be aware of the spectrum of diseases in their respective countries for effective healthcare planning. This is especially true given that cancers are becoming more common. It is also important to be aware of the spectrum of illnesses including cancers in the expatriate population considering that they can make up a large proportion of the population and the workforce. Breast and cervix cancers which are also common among the expatriate population, can be easily detected in the early stages through regular practice of manual self-breast examinations or mammography and Pap smear. Therefore, it is important that any health related programs include the foreign nationals working in the country. Early detection allows more effective and less costly treatment which is beneficial. Educations through Medias, information leaflets during employment checks and even health awareness programs may be effective.

In conclusion, this study reports on the spectrum of cancers diagnosed among the non-immigrant South-East Asian working in Brunei Darussalam, a developing South-East Asian nation. The most common cancers were cancers of the digestive system followed by cancers affecting the female gender, breast and reproductive/ gynecological system. The spectrum of cancers among the different nationalities differ and this can be accounted for by the demographic of the foreign nationals working in the country; young, differences in the proportion of male and female depending on the sectors. Further studies on this group are required from other countries to see if our findings are reflective of South-East Asian nationals working elsewhere.

\section{References}

Ali R, Barnes I, Cairns BJ, et al (2013). Incidence of gastrointestinal cancers by ethnic group in England, 20012007. Gut, 62, 1692-703.

Chang HJ, Chen WX, Lin EC, et al (2014). Delay in seeking medical evaluations and predictors of self-efficacy among women with newly diagnosed breast cancer: a longitudinal study. Int J Nurs Stud, 51, 1036-47.

Eav S, Schraub S, Dufour P, et al (2012). Oncology in cambodia. Oncol, 82, 269-274.

Giddings BH, Kwong SL, Parikh-Patel A, Bates JH, Snipes KP (2012). Going against the tide: increasing incidence of colorectal cancer among koreans, filipinos, and south asians in california, 1988-2007. Cancer Causes Control, 23, 691-702.

International Agency for Research on Cancer. Globocan 2012: Estimated cancer incidence, mortality and Prevalence Worldwide 2012.

Jung M, Ramanadhan S, Viswanath K (2013). Effect of information seeking and avoidance behavior on self-rated health status among cancer survivors. Patient Educ Couns, 92, 100-6.

Laudico AV, Mirasol-Lumague MR, Mapua CA, et al (2010). Cancer incidence and survival in metro Manila and Rizal Province, Philippines, Jpn J Clin Oncol, 40, 603-12.

Maringe C, Mangtani P, Rachet B, et al (2013). Cancer incidence in South Asian migrants to england, 1986-2004: unraveling ethnic from socioeconomic differentials. Int J Cancer, 132,
Cancers among South-East Asian Nationals in Brunei Darussalam 1886-94.

Menon U, Szalacha LA, Prabhughate A (2012). Breast and cervical cancer screening among South Asian immigrants in the United States. Cancer Nurs, 35, 278-87.

Moore MA, Ariyaratne Y, Badar F, et al (2010). Cancer epidemiology in South Asia - past, present and future. Asian Pac J Cancer Prev, 11, 49-66.

Moore MA, Attasara P, Khuhaprema T, et al (2011). Cancer epidemiology in mainland South-East Asia - past, present and future. Asian Pac J Cancer Prev, 11, 67-80.

Moore MA, Manan AA, Chow KY, et al (2010). Cancer epidemiology and control in peninsular and island SouthEast Asia - past, present and future. Asian Pac J Cancer Prev, 11, 81-98.

National cancer registry report. Malaysia cancer statistics- data and figure 2007.

National Registry of Disease Office (NRDO). Singapore cancer registry interim annual registry report trends in cancer incidence in Singapore 2008-2012. https://www. nrdo.gov.sg/docs/librariesprovider3/Publications-Cancer/ trends-in-cancer-incidence-in-singapore-2009-2013-interim. pdf?sfvrsn=0 (Retrieved $18^{\text {th }}$ March 2015).

Othman NH, Nor ZM, Biswal BM (2008). Is Kelantan, joining the global cancer epidemic?--experience from hospital Universiti Sains Malaysia; 1987-2007. Asian Pac J Cancer Prev, 9, 473-8.

Teo MC, Soo KC (2013). Cancer trends and incidences in Singapore. Jpn J Clin Oncol, 43, 219-24.

Vuong DA, Velasco-Garrido M, Lai TD, Busse R (2010). Temporal trends of cancer incidence in Vietnam, 1993-2007. Asian Pac J Cancer Prev, 11, 739-45.

Wahidin M, Noviani R, Hermawan S, et al (2012). Populationbased cancer registration in Indonesia. Asian Pac J Cancer Prev, 13, 1709-10.

Wirasorn K, Suwanrungruag K, Wiangnon S, Punjaruk W (2014). Numbers of new cases and trends of cancer 19932012: srinagarind hospital based population, Khon Kaen, north- East Thailand. Asian Pac J Cancer Prev, 15, 8423-7.

Woodward M (2014). A Consensus plan for action to improve access to cancer care in the association of southeast asian nations (ASEAN) region. Asian Pac J Cancer Prev, 15, 8521-6. 